\title{
The Impact of Multimodal Texts on Reading Achievement: A Study of Iranian Secondary School Learners
}

\author{
Bahareh Baharani \\ Department of English, Khorasan e Razavi Science and Research Branch, Islamic Azad University, Neyshabur, Iran \\ Department of English, Neyshabur Branch, Islamic Azad University, Neyshabur, Iran \\ E-mail: b.baharani@hotmail.com \\ Narjes Ghafournia (Corresponding author) \\ Department of English, Neyshabur Branch, Islamic Azad University, Neyshabur, Iran \\ E-mail: narjesghafournia@yahoo.com
}

Received: 08-12- 2014

Published: 01-07- 2015
Accepted: 10-02- 2015

doi:10.7575/aiac.ijalel.v.4n.4p.161
Advance Access Published: February 2015

URL: http://dx.doi.org/10.7575/aiac.ijalel.v.4n.4p.161

\begin{abstract}
This study was designed to investigate the impact of multimodal text on reading comprehension test performance of Iranian intermediate learners. A total of 80 students participated in this study. All of them were Iranian female EFL learners with the age ranging from 16 to 18. They were selected from a boarding high school in Nasr Abad, Torbat Jam in Khorasan e Razavi, Iran. The students were randomly settled in four groups, who received different instructional approaches through using linear texts, multimodal printed texts, non-printed multimodal texts, and both multimodal printed and non-printed texts. A pre-test and post-test were used to find out the differences before and after the experimental treatment. The results reflected that the printed and non-printed multimodal texts had significant impact on reading comprehension test performance. In contrast, applying linear texts or traditional texts did not exert significant influence on reading comprehension ability of the participants. The findings provide useful hints for language instructors to improve effectiveness of instructional reading curriculums and reading ability of language learners. The participants who learned reading comprehension through using multimodal printed and non-printed texts enjoy reading programs and develop their intrinsic and extrinsic motivation for improving reading ability.
\end{abstract}

Keywords: multimodal printed text, multimodal non-printed text, linear text, motivation, reading comprehension

\section{Introduction}

In recent years, Information Communication Technology (ICT) has provided EFL learners with many opportunities to learn English with relative ease through conforming them to multimodal texts (Verhoeven \& Perfetti, 2008). There is protracted debate over the textual shift for today's students, who are faced with an environment full of visual, electronic and digital texts called "multimodal text" (Walsh, 2007, p.26). The above-mentioned discussion leads to another challenge concerned with the type of pedagogies or theories that can be applied in multimodal learning environments. Although traditional literacy approaches have placed great emphasis on printed and linear texts, modern teaching approaches put great emphasis on multimodal texts and digital technology (Kress \& Van Leeuwen, 1996, 2001).

As Walsh (2007) indicated, printed or linear texts are monomodal texts, whereas multimodal texts are concerned with a variety of sensory modes, working in a synchronized way to convey meaning. It means that a multimodal text can be a combination of spoken and written languages, still or moving images, which can be presented on paper or electronic screen. It is inferred from the definition that multimodal texts can be divided into two types of texts. The first type of text is printed texts, such as picture books, newspapers, magazines, and information books. In comparison, the second type of text is concerned with non-printed texts such as videos, films, and, digital media. Good examples of digital media are CD ROOMs or DVDs and texts through electronic screen such as e-mails and internet. To put it simply, a multimodal text enables language learners to read comprehensively through using different learning channels (Verhoeven \& Perfetti, 2008). In an experimental study, Mayer and Gallini (1990) asked students to read expository passages, related with the way scientific devices work. Each passage contained either no illustrations, static illustrations of the device with labels for each part, static illustrations of the device with labels for major actions, or dynamic illustrations, showing off or on states of the device along with labels for each part and each major action. The results indicated that the parts and steps illustrations consistently improved performance on recall of conceptual information and problem solving retention. The findings of Mayer and Gallini's study on modality representation showed that the language learners who read a text with illustrations were more successful in accomplishing problem solving tasks and transferring knowledge than the learners who read a text with no illustrations.

One of the main problems of Iranian language learners, particularly secondary school learners is their poor performance in reading comprehension tests (Karimi, 1386). Many L2 readers are engaged in slow and laborious reading process, which is due to underdeveloped word recognition of target words, lower level phonological processing, and inability to 
derive meaning from the texts (Grabe, 2004; Grabe \& Stoller, 2002; Kuhn \& Stahl, 2003). Slow readers lack enough motivation and self-efficacy for processing target language reading; therefore, they cannot get gist of meaning suffering from poor reading comprehension ability (Koda, 2005). Koda described a similar scenario, in which inadequate reading practice among poor readers does not let them develop their conceptual growth. Day and Bamford (1998) believed that reading practice helps L2 learners have access to necessary linguistic, world, and topical knowledge to improve their reading skills. One probable explanation is concerned with the excessive use of linear texts with no pictures and illustrations. It should be kept in mind that Iranian language learners, like any other foreign language learners, have limited vocabulary knowledge. Therefore, the use of multimodal texts in printed or non-printed forms by language teachers can help language learners predict the content better leading to more effective long-lasting comprehension.

Therefore, this study tried to find out whether reading comprehension test performance of Iranian high school language learners at intermediate level was significantly affected by employing multimodal texts in language teaching classes. Furthermore, this study attempted to investigate the differences among the test performances of four groups of participants who used four types of texts in their learning environments, including printed multimodal texts, non-printed multimodal texts, combination of both texts, and linear traditional texts. The findings were of significance as they revealed the significant influence of using multimodal texts in contrast with linear texts on EFL learners' reading achievement at the intermediate level. Furthermore, the findings reflected the extent to which different ways of multimodal presentation of reading texts influenced language learners' test performance.

The objectives of the study were achieved through answering the following questions:

1. Do multimodal printed English texts significantly affect Iranian students' reading comprehension achievement?

2. Do non-printed multimodal English texts significantly affect Iranian students' reading comprehension achievement?

3. Do multimodal printed English texts and multimodal non-printed English texts significantly affect Iranian students' reading comprehension achievement?

The relevant null hypotheses were reformulated as follows:

1. Multimodal printed English texts do not significantly affect Iranian students' reading comprehension achievement.

2. Non-printed multimodal English texts do not significantly affect Iranian students' reading comprehension achievement.

3. Multimodal printed English texts and multimodal non-printed English texts do not significantly affect Iranian students' reading comprehension achievement.

\section{Review of Literature}

\subsection{A Theoretical Framework for Multimodal Text Analysis}

Halliday's (1976) systemic-functional linguistics (SFL) described language as a system with meaning potential. Halliday defined language as "a set of options in a stated environment" (p. 26) that were formed by how people use them to make meaning. He provided a tri-functional framework of meaning: ideational, interpersonal, and textual. Ideational meanings relate to what is going on in the world, which means how people get use of language to talk about their experiences. They relate to the way of using words in order to express actions, objects, places, events, people, things, qualities, and ideas. They deal with how people show their experiences concerning the type of processes and participants they use. Interpersonal meanings are related to the ways language is used to arrange the kind of speakerlistener interaction and how such interaction is settled. Textual meanings are concerned with how textual factors are composed of coherent messages relevant to context of situation.

\subsection{Multimedia Learning}

In multimedia learning, the learner deals with three significant cognitive processes: selecting, organizing, and integrating. Selecting is used for incoming verbal information to produce a text base. It is also applied to incoming visual information to produce an image base. Organizing, as the second cognitive process, is applied to the word base to construct a verbal-based model to be-explained system. It is also applied to the image base to construct a visually-based model to be-explained system. In the verbally-based model and visually-based model, integrating happens when the learner creates connections between corresponding events (or states). Mayer (1997) explained the model in detail and created a series of experiments, consisting of five major principles of how to use multimedia to help students easily understand the model. The principles are further discussed.

\subsubsection{Multiple Representation Principle}

Giving an explanation in words and pictures is better than an explanation only in words. According to the first principle, presenting an explanation using two modes of presentation is better than using only one mode of presentation. As an example, students who listened to a narration explaining how a bicycle tire pump works and at the same time had to view the corresponding animations provided more useful solutions to the subsequent problem-solving transfer questions than did the students who listened to the same narration without viewing any animations (Mayer \& Anderson, 1991, 1992). Likewise, the students who read a text consisting of the captioned descriptions near the corresponding words generated about $65 \%$ more useful solutions to a subsequent problem-solving transfer test than did the counterpart students, who simply read the text (Mayer, 1989; Mayer \& Gallini, 1990). The result indicates a multimedia effect, which is consistent with a cognitive theory of multimedia learning. Because students believed that multimedia 
explanations could build two different mental representations, which were verbal and visual models, enabling them to build connections between them.

\subsubsection{Contiguity Principle}

Contiguity principle is concerned with simultaneous presentation of words and pictures rather than separate presentation of them. In other words, the principle is concerned with presenting related words and pictures at the same time, which substantially enhances students' comprehension and retention. The findings of some studies (e.g., Mayer \& Anderson, 1991, 1992; Mayer \& Sims, 1994) demonstrated that the students who listened to a narration about how a bicycle tire pump works while at the same time viewed the related animation generated 50\% more useful problem-solving solutions than did the counterpart students, who solely viewed the relevant information before or after listening to the narration. Likewise, the findings of other studies reflected that the students who read a text giving an explanation of how tire pumps work with captioned descriptions generated about $75 \%$ more useful solutions on problem-solving transfer questions than did the counterpart students, who read the same text and descriptions, presented on separate pages (Mayer, 1989; Mayer, et.al, 1995). The result is called a contiguity effect. Parallel patterns have been presented by other researchers (Chandler \& Sweller, 1991; Sweller \& Chandler, 1994; Sweller, et.al, 1990; Paas \& Van Merrienboer, 1994). This result is consistent with cognitive theory of multimedia learning as corresponding words and pictures must be in working memory at the same time for facilitating construction of referential links among them.

\subsubsection{Split-Attention Principle}

When giving a multimedia explanation, presenting a word as auditory narration is better than presenting it as visual onscreen text. The third principle is that words should be presented in auditory mode rather than in visual mode. As an example, the students who viewed an animation illustrating the formation of lightning while simultaneously listening to a corresponding narration generated approximately $50 \%$ more useful solutions on a following problem-solving transfer test than did the counterpart students, who viewed the same animation with corresponding on-screen text, comprising similar narration words (Mayer \& Moreno, in press). It is called a split attention effect (Chandler \& Sweller, 1991; Mousavi, et al, 1995; Sweller, et al, 1990). The result is in accordance with cognitive theory of multimedia learning, as the on-screen text and animation can overload visual information processing system while the narration is processed in the verbal information processing system, and the animation is processed in the visual information processing system.

\subsubsection{Individual Differences Principle}

The above mentioned principles are more significant for intelligent people than slow people. According to the fourth principle, multimedia effects, contiguity effects, and split-attention effects depend on individual differences in learners. For example, the students who have deficiency in prior knowledge are apt to show stronger multimedia effects and contiguity effects than the students who have high levels of prior knowledge (Mayer \& Gallini, 1991, Mayer, et al, 1995). According to Mayer's, et al cognitive theory of multimedia learning, students with high prior knowledge may be able to produce their own mental images while listening to an animation or reading a verbal text, so having a contiguous visual presentation is not needed. Also, Mayer and Sims (1994) found that the students who have high scores on spatial ability tests showed greater multimedia effects than did the students who had low scores on spatial ability tests. Thus, the students with high spatial ability are able to keep the visual image in visual working memory and are highly probable to take advantage of contiguous presentation of words and pictures.

\subsubsection{Coherence Principle}

The fifth principle asserts that students learn better from a coherent summary. This principle puts particular emphasis on learning through relevant words and pictures in a text. For instance, the students who read a text along with corresponding illustrations about the steps of lightning generated $50 \%$ more useful solutions on a succeeding problemsolving transfer test than did the students who read the same information with extra language details (Harp \& Mayer, 1997; Mayer, et al, 1996). The use of relevant pictures and words to get gist of meaning is called the redundancy effect by the researchers (Bobis, et al, 1993; Chandler \& Sweller, 1991). This result is consistent with cognitive theory of multimedia learning in that a shorter visual presentation makes learners choose related information and organize relevant information productively.

Being familiar with the theory of how learners process multimedia information enables researchers to accomplish focused research using some preliminary principles of multimedia learning. Although the principles are subject to further investigations, they encourage teachers to implement learner-centered approaches and multimedia instruction, which is a great success.

\subsection{Modeling Text Comprehension Processes}

Perfetti (1999) believed that the extent of reading comprehension depends on students' prior knowledge. Prefetti explained that reading comprehension process begins with recognition of individual words. It means that visual input changes into linguistic representations and comprehension of a text that requires word- to-text combining. As a result, Verhoeven and Perfetti (2008) proved that readers build situation models as they try to comprehend a text. They found that there are two levels of representation: a model of the propositions of a text (text model) and a model of what a text is about (situation model). Furthermore, they believe that comprehending a text cannot be completely clear; therefore, a reader makes inferences about what is in the text based on his/her prior knowledge.

Mayer (2009) noted that multimedia presentation provides many possibilities to ease constructing knowledge. Similarly, Verhoeven and Perfetti (2008) proposed that researchers should examine how students learn from multimedia texts, particularly when ICT (Information and Communication Technology) is stressed in instructional curriculums. Mayer (2009) noted that cognitive theory of multimedia learning was established according to the idea that there are various 
processing systems for two kinds of information. Verhoeven and Perfetti believed that the factors which are combined with multimedia cognitive theory present the opportunities to ease teaching and learning comprehension. In addition, they asserted that processing verbal information usually includes comprehension of written text, which can be considered as a secondary language process, partially obtained from primary spoken language processes, or an audio or verbal illustration of words.

Different multimedia presentations provide the chance for students to make use of words and pictures. Mayer (2010) asserted that using a mixture of words and pictures is better than using words alone. When students are watching and listening, they comprehend better than when they are solely watching (Mayer \& Mereno, 1998). Briefly, multimedia can enhance students' reading comprehension achievement.

Likewise, Verhoeven and Perfetti (2008) detected that basic models of text comprehension, such as resonance model (Gerrig \& McKoon, 1998), construction, integration model (Kintsch, 1988), and landscape model (Van den Broek, et al, 1996), have shown that text comprehension cannot be accomplished solely by the information that is present in the text. Based on the models, the learners have to apply their knowledge to construct new knowledge, which is related to their experiences and situations to process reading comprehension texts. Verhoeven and Perfetti (2008) believed that the factors which are combined in multimodal text processing let learners make inferences about what is in the text based on their prior knowledge.

In the study done by Son (2003), the effect of three types of reading text formats was investigated. The text formats were: paper-based format (PF), computer- based non-hypertext format (NHF), and computer-based hypertext format (HF). The purpose of the study was to detect the degree of usefulness of hyperlinks on the online lexical resources, which presented readers with optional help during independent reading. The finding indicated that integration of text with sound and images actually made comprehension of reading text quite easy and led to better pronunciation and more effective contextual use of lexical items than conventional paper-based texts.

Also, Kuo, et al (2010) administered a study to examine the effect of multimedia, specifically Reading Comprehend Platform (RCP), on students' reading comprehension. RCP concentrated on the integration of different multimedia. The result revealed that the students showed a high interest in RCP and reading comprehension. Therefore, the researcher concluded that the Platform increased students' performance in English reading comprehension. Thus, he asked for further research to examine other types of multimedia that can influence students' reading comprehension. Segers and Hulstijn-Hendrikse (2008) examined the effect of cognitive processes, underlying multimedia text learning among the students in basic schools. Applying different formats, the students were taught reading comprehension lessons. The formats were seen in written presentation, which was accompanied by pictures, oral presentation, and oral presentation with pictures. The findings demonstrated that the students using oral presentation with pictures did better than the students using written presentation without pictures. The theoretical framework of this study is concerned with Mayer's (2010) cognitive theory of multimedia learning as well as cognitive processes underlying text comprehension based on Verhoeven and Perfetti's (2008) model. According to Mayer's (2010) model, a meaningful learning happens when students choose suitable words and pictures, organize them into coherent pictorial and verbal models, combine them with each other, and use proper prior knowledge. Mayer believed when corresponding verbal and pictorial representation are processed in working memory simultaneously, active learning processes can take place. Mayer (2010) explained when given information is similar to cognitive processes, which take place inside a learner, the learner learns better. This helps the learner achieve information and store it in his/her long-term memory. If the presented information is only a text, a learner cannot comprehend the text, but also he/she can use his/her prior knowledge to construct new knowledge. In the middle of this process, the reader involves two levels of representation: the text model, a model of propositions of a text, and the situation model, a model of what the text is about (Verhoeven \& Perfetti, 2008). Verhoeven and Perfetti proposed that through using other sources of information, readers read more comprehensively than the readers who use only a printed text. Thus, in multimodal text processing, the learners who use more than one source of information (text and picture) are expected to read more comprehensively.

Finally, Verhoeven and Perfetti (2008) asserted that multimodal text enhanced students' reading comprehension achievement because students read comprehensively using more than one channel (Verhoeven \& Perfetti, 2008). According to Mayer's (2009) cognitive theory of multimedia learning, meaningful learning occurs when the students are engaged in active processing within two channels. Therefore, the students who make use of multimedia texts may read more comprehensively in comparison with the students who use conventional reading comprehension texts and use text model.

The aim of this study is to explore the probable effect of applying multimodal printed and non-printed English texts on reading comprehension achievement of Iranian high school students. The findings are of significance as the use of multimodal texts enhances language learning process and encourages language learners to adopt a positive attitude toward language learning.

\section{Methodology}

\subsection{Participants}

A total of 80 students participated in this study. All of them were Iranian female EFL learners with the age ranging from 16 to 18. They were selected from Ayatollah Khamenei boarding school in Nasr Abad, Torbat Jam. The participants were at the intermediate level of language proficiency. Thus, they shared similar linguistic and cultural background. 


\subsection{Instrumentation}

To investigate the purpose of this study, a pre-test, post-test, and Oxford Placement Test (OPT) were used. Through using Oxford Placement Test, the participants with intermediate proficiency level were selected, who were randomly divided into four groups. One group was considered as a control group, whereas the other three groups were regarded as experimental groups. The pre-test was also used as the post-test to avoid any inequality between them. Every item was graded dichotomously. In other words, one score was given for a correct answer, and zero score was given for an incorrect answer. The allotted time to answer either pre-test or post-test was 30 minutes. The pre-test and post-test contained three reading passages: The Wolf and Seven Little Kids; The Frog King; and Godfather Death, chosen from Brother Grimm's Fairy Tales. Each text was followed by 20 multiple-choice questions. The test was given to some TEFL instructors, who provided feedback on the content of the test to remove the probable ambiguities. The test was administered to 30 participants, who also gave their feedback on the test items. The necessary revisions were made by the researcher to improve the content validity of the test. The reliability coefficient of the test was calculated by using a KR-21 formula $(a=.090)$. In the experimental phase, three types of web-based linear reading passages were used. The passages were derived from Wolf and Seven Little Kids, Godfather Death and Frog King. The reading texts were linear printed texts with no illustrations, multimodal printed texts (reading passage with pictures) and non-printed multimodal texts.

\subsection{Procedure}

An Oxford Placement Test was administered to all the participants in order to single out a group of homogeneous participants. An Oxford Placement Test consisted of three parts: structure, vocabulary, and reading comprehension. Initially, 120 female students participated in this study. After administration of OPT, 80 intermediate students, whose scores were between 32 and 79 (between \pm one standard deviation) were selected. The selected participants were at the intermediate level of language proficiency. They were randomly divided into four groups. One group was considered as a control group, and the other three groups were regarded as experimental groups. All the participants took the pre-test one week prior to the experiment. The pre-test measured the participants' reading comprehension ability before receiving the designated treatment. Within eight weeks, each group received different teaching approaches by the researcher. The same text was taught in each group, but the first group or the control group received a traditional approach through using linear texts by the researcher. The second group received multimodal printed texts, accompanied by pictures. The third group received non-printed reading multimodal texts, such as related video films, accompanied by English subtitles. The fourth group received both multimodal printed texts (reading text with pictures) and non-printed text (related videos with English subtitle). The treatment lasted more than two months. In the last session, all groups took the same post-test. The results revealed whether the use of different types of text had a significant effect on reading achievement of four groups. In this study, the researcher attempted to explore the effect of using different types of multimodal texts in English classes on reading comprehension achievement of the participants. As a cause and effect relationship was explored, and random sampling was utilized to recruit the sample, the design of the study was experimental. To probe the corresponding research questions and null-hypotheses, a set of parametric statistical analyses such as descriptive statistics, one-way analysis of variance, and a Tukey HSD test were utilized in this study.

\section{Results and Discussion}

\subsection{Parametric Assumptions}

This study aimed to investigate the effect of multimodal printed English texts on improving reading comprehension ability of Iranian EFL learners. A one-way analysis of variances was run to answer the research questions. Before discussing the results, it should be mentioned that the four assumptions, associated with parametric tests were met. First, the data were measured on an interval scale. Second, the groups performed independently on the tests, i.e. no treatment involving group of pair work was administered. Third, the data enjoyed normal distributions. As displayed in Table 4.1, the ratios of skewness and kurtosis over their respective standard errors were within the ranges of $+/-1.96$.

Table 4.1. Testing Normality Assumption

\begin{tabular}{llllllll}
\hline Group & \multicolumn{3}{c}{ Skewness } & \multicolumn{3}{c}{ Kurtosis } \\
\cline { 3 - 8 } & \multicolumn{3}{c}{ StatisticStd. ErrorRatioStatisticStd. ErrorRatio } \\
\hline Multimodal PNPPre-test & .087 & .512 & 0.17 & -.664 & .992 & -0.67 \\
\multirow{4}{*}{ Multimodal NP Pre-test } & -.178 & .512 & -0.35 & -.589 & .992 & -0.59 \\
& Post-test & .512 & 0.71 & -.828 & .992 & -0.83 \\
Multimodal P & Post-test & .069 & .512 & 0.13 & -.460 & .992 & -0.46 \\
& Pre-test & .119 & .512 & 0.23 & .532 & .992 & 0.54 \\
\cline { 2 - 7 } Control(Control)Pre-test &.- .089 & .512 & -0.17 & -1.095 & .992 & -1.10 \\
& Post-test & -.461 & .512 & -0.90 & -.578 & .992 & -0.58 \\
& Post-test & -.167 & .512 & -0.33 & -.631 & .992 & -0.64 \\
\hline
\end{tabular}

$$
\text { Note. PNP }=\text { Printed and Non-Printed }, \quad \text { NP }=\text { Non-Printed } \quad \mathrm{P}=\text { Printed }
$$

The last assumption - homogeneity of variances - is discussed when reporting the results of the one-way ANOVA. 


\subsection{Pre-test of Reading Comprehension}

A one-way analysis of variances was run to compare the mean scores of the four groups on the pretest of reading comprehension in order to prove that they enjoyed the same level of reading comprehension ability prior to the administration of the treatments. Before discussing the results, it should be mentioned that the groups enjoyed homogeneous variances on the pretest of reading comprehension. As displayed in Table 4.2, the Levene's F-value of .831 was not significant at $(\mathrm{P}<.05)$.

Table 4.2 Test of Homogeneity of Variances

\begin{tabular}{cccc}
\hline Levene Statistic & $\mathrm{df1}$ & $\mathrm{df} 2$ & Sig. \\
\hline .831 & 3 & 76 & .481 \\
\hline
\end{tabular}

Table 4.3 displayed descriptive statistics of the four groups on the pretest of reading comprehension.

Table 4.3 Descriptive Statistics of Reading Comprehension Pretest

\begin{tabular}{lcccc}
\multicolumn{5}{l}{ Table 4.3 Descriptive Statistics of Reading Comprehension Pretest } \\
& $\mathrm{N}$ & Mean & Std. Deviation & Std. Error \\
& & & & \\
\hline Multimodal PNP & 20 & 9.40 & 1.314 & .294 \\
Multimodal NP & 20 & 9.50 & 1.504 & .336 \\
Multimodal P & 20 & 10.05 & 2.089 & .467 \\
Control & 20 & 10.30 & 1.689 & .378 \\
Total & 80 & 9.81 & 1.685 & .188 \\
\hline
\end{tabular}

$\mathrm{P}=$ Printed, $\mathrm{NP}=$ Non Printed, PNP $=$ Printed and Non Printed

As displayed in Table 4.3, the multimedia, printed and non-printed $(\mathrm{M}=9.40, \mathrm{SD}=1.31)$, multimedia non-printed $(\mathrm{M}=$ $9.50, \mathrm{SD}=1.50)$, multimedia printed $(\mathrm{M}=10.05, \mathrm{SD}=2.08)$, and control $(\mathrm{M}=10.30, \mathrm{SD}=1.68)$ groups showed similar means on pretest. The means of the four groups in the pretests are shown in Figure 4.1.

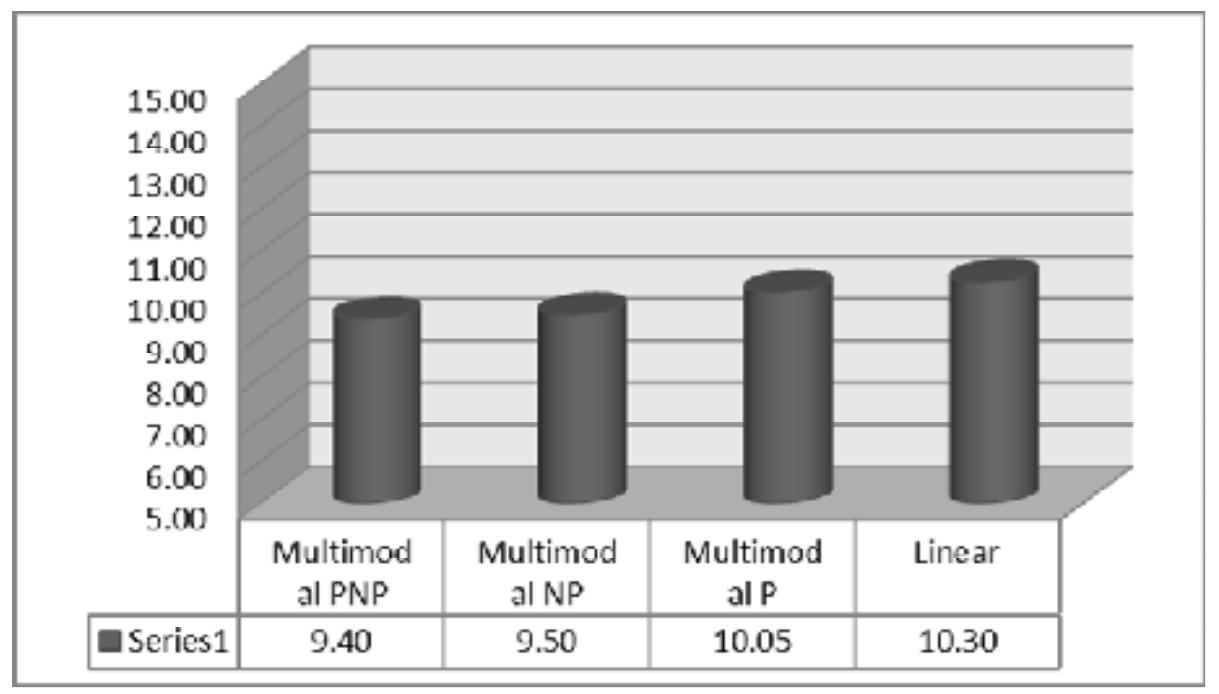

Figure 4.1 Pretest of Reading Comprehension

Figure 4.1 demonstrated the mean scores of the four groups in reading comprehension pretest. The mean scores are close and not significantly different. To explore the differences among the mean scores of the four groups, a one-way ANOVA was conducted. The results are shown in Table 4.4.

Table 4.4 A One-Way Analysis of Variance for Reading Comprehension Pretest

\begin{tabular}{lccccc}
\hline & Sum of Squares & df & Mean Square & F & Sig. \\
\hline Between Groups & 11.238 & 3 & 3.746 & 1.337 & .269 \\
Within Groups & 212.950 & 76 & 2.802 & & \\
Total & 224.188 & 79 & & & \\
\hline
\end{tabular}

The results of one-way ANOVA, $\mathrm{F}(3,76)=1.337, \mathrm{P}<.05, \omega^{2}=.012$ presented a weak effect size. The results indicated that there were not any significant differences among the means of the four groups on the pre-test of reading comprehension. Thus, four groups' means on the pretest of reading comprehension were homogenous, and all the participants enjoyed nearly the same level of reading comprehension ability prior to the administration of the treatments. 


\subsection{Post-test of Reading Comprehension}

A one-way ANOVA was run to compare four groups' mean scores on the posttest of reading comprehension in order to probe three research questions, posed in this study. The ANOVA test was followed by post-hoc Tukey tests to compare the groups two by two. Before discussing the results, it should be mentioned that the groups enjoyed homogeneous variances on the posttest of reading comprehension. As displayed in Table 4.5, the Levene's F-value of 1.99 was not significant $(\mathrm{P}<.05)$.

Table 4.5 Test of Homogeneity of Variances in Posttest

\begin{tabular}{cccc}
\hline Levene Statistic & $\mathrm{df1}$ & $\mathrm{df} 2$ & Sig. \\
\hline 1.994 & 3 & 76 & .122 \\
\hline
\end{tabular}

Table 4.6 displayed the descriptive statistics of four groups in the posttest of reading comprehension.

Table 4.6 Descriptive Statistics for Reading Comprehension Posttest

\begin{tabular}{lllll}
\hline & N & Mean & Std. Deviation & Std. Error \\
\hline Multimodal PNP & 20 & 14.50 & 1.701 & .380 \\
Multimodal NP & 20 & 14.10 & 1.071 & .240 \\
Multimodal P & 20 & 16.00 & 1.747 & .391 \\
Control & 20 & 11.10 & 1.774 & .397 \\
Total & 80 & 13.93 & 2.380 & .266 \\
\hline
\end{tabular}

The multimedia, printed group $(\mathrm{M}=16, \mathrm{SD}=1.74)$ showed the highest mean score in the post-test. This was followed by the multimedia, printed and non-printed $(\mathrm{M}=14.50, \mathrm{SD}=1.70)$ and multimedia non-printed $(\mathrm{M}=14.10, \mathrm{SD}=1.07)$ groups successively, which showed similar means in the posttest. The control group showed the lowest mean score (M $=11.10, \mathrm{SD}=1.77)$. The results of one-way ANOVA, F $(3,76)=32.92, \mathrm{P}<.05, \omega^{2}=.54$ presented a large effect size, indicating significant differences among the means of four groups in the posttest of reading comprehension. The results are shown in Table 4.7.

Table 4.7 One-Way ANOVA for Posttest of Reading Comprehension

\begin{tabular}{lccccc}
\hline & Sum of Squares & df & Mean Square & F & Sig. \\
\hline Between Groups & 252.950 & 3 & 84.317 & 32.929 & .000 \\
Within Groups & 194.600 & 76 & 2.561 & & \\
Total & 447.550 & 79 & & & \\
\hline
\end{tabular}

As shown in Table 4.7, F-value of 32.92 at $\mathrm{p}=.000$ indicated significant differences among the means of four groups. A post-hoc Tukey test (Table 4.8) was run to compare the mean scores of the groups two by two in order to probe the research questions. The results are shown in Table 4.8 .

Table 4.8 Post-Hoc Tukey Tests for the Posttest of Reading Comprehension

(I) Group $\quad$ (J) Group $\quad$ Mean Difference (I-J)Std. ErrorSig.

\begin{tabular}{llccc}
\hline Multimodal PNPMultimodal NP & .400 & .506 & .859 \\
& Control & $3.400^{*}$ & .506 & .000 \\
Multimodal NP & Control & $3.000^{*}$ & .506 & .000 \\
Multimodal P & Multimodal PNP & $1.500^{*}$ & .506 & .021 \\
& Multimodal NP & $1.900^{*}$ & .506 & .002 \\
& Control & $4.900^{*}$ & .506 & .000 \\
\hline
\end{tabular}

*. The mean difference is significant at the 0.05 level.

The results indicated that there was a significant difference between multimedia printed and control groups $(\mathrm{MD}=4.90$, $\mathrm{P}<.05)$. Based on these results, the first null-hypothesis as multimodal printed English texts did not significantly affect Iranian students' reading comprehension achievement was strongly rejected. The multimedia printed group also outperformed the control group on the posttest of reading comprehension. There was a significant difference between the mean of multimedia non-printed $(\mathrm{M}=14.10)$ and control group $(\mathrm{M}=11.10)(\mathrm{MD}=3, \mathrm{P}<.05)$. Based on these results, the second null-hypothesis as non-printed multimodal English texts did not significantly affect Iranian students' reading comprehension achievement was strongly rejected. The multimedia non-printed group outperformed the control 
group on the posttest of reading comprehension. There was a significant difference between multimedia, printed $(\mathrm{M}=$ 16) and multimedia non-printed group $(\mathrm{M}=14.10)(\mathrm{MD}=1.90, \mathrm{P}<.05)$. Based on these results, the third nullhypothesis as multimodal printed English texts and multimodal non-printed English texts did not significantly affect Iranian students' reading comprehension achievement was strongly rejected. The multimedia printed group outperformed the multimedia non-printed group on the posttest of reading comprehension. Figure 4.2 demonstrates the mean scores of four groups in the post tests of reading comprehension tests.

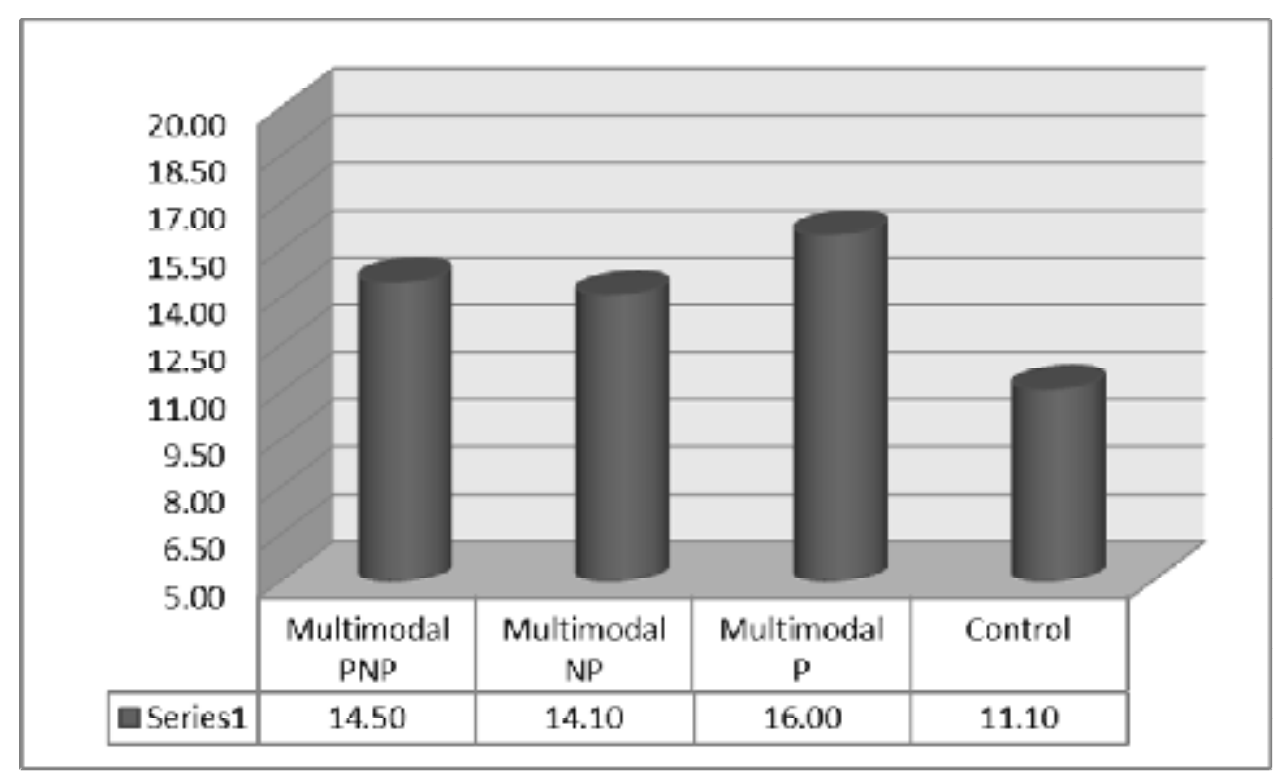

Figure 4.2 Means of the Posttest of Reading Comprehension for the Four Groups

As demonstrated in Figure 4.2, the mean score of multimodal printed text was the highest among the mean scores of the other groups.

The findings of this study confirm Verhoeven and Perfetti's (2008) finding in that multimodal text enables language learners to read comprehensively through using different learning channels. The findings of Mayer and Gallini's (1990) study of modality representation was also proved in this study in that language learners who read a text with illustrations were more successful in accomplishing problem solving tasks and transferring knowledge than the learners who read a text with no illustrations. One probable explanation for the impact of multimodal texts on reading comprehension test performance resides in the way different modes are processed and the way particular modes activates a reader's meaning-making process. Thus, in multimodal texts, a reader uses various senses, including sight, hearing, tactile, and kinesthetic to react to different modes and channels for effective learning (Walsh, 2007).

\section{Conclusion and Pedagogical Implications}

Based on the findings of the present study, the use of multimodal texts has a significant impact on Iranian intermediate learners' reading comprehension achievement. It is worth mentioning that the students with high level of reading proficiency had better performance than did the other students. Using multimodal texts created more joy among the students who used multimodal texts. The role of the teachers should not be taken for granted here. Raising a learner's reading comprehension ability requires language teachers to identify the major factors that influence the reader's comprehension ability. Taylor et al (2000) noted that students have some particular characteristics that can limit or improve their capacity to comprehend text. These characteristics comprise the reader's attention span, short-term memory, reasoning skills, motivation, knowledge of comprehension strategies, ability to concentrate and decode meaning, grammatical knowledge, and background schemata. Taylor et al (2000) introduced attention span as an important factor in a student's reading success. Through attention span, a reader can identify a meaningful connection between two elements if he/ she sees them at the same time.

Block and Pressley (2002) stressed that existing research points to the fact that teachers must teach valid and accurate comprehension strategies to enhance students' reading comprehension. It should be noted that appropriate modeling develop students' comprehension success. In their book "Integrating Language Arts through Literature and Thematic Units", Roe and Ross (2006) recommended that teachers should teach one or two strategies to students rather than many strategies to decrease the risk of confusion. Furthermore, teachers should represent strategic techniques in a real-life reading setting to engage the students in authentic activities (Roe \& Ross, 2006). In such an authentic atmosphere, students can learn reading strategies to improve their ability to comprehend texts if they receive proper, explicit, and direct instruction.

It should be kept in mind that Iranian language learners, like any other foreign language learners, have limited vocabulary knowledge. Therefore, the use of multimodal texts by language teachers can help language learners predict the content better leading to more effective long-lasting comprehension. As a result, learners who learn with words and pictures learn reading content more effectively and remember it better. The result of the study implies that guessing 
the story content from pictures was highly effective in increasing the learners' reading comprehension ability. Chayaburakul (2003) maintained that pictures provide implication for the reader to make intelligent guessing. Reading pictures motivate the readers and capture their attention to the content of reading materials as well as reading tasks. Bowen (1982) explained that variation of pictures stimulates language learners' thinking process to gain a far better understanding of the reading passage.

The findings of this study manifested the great need to include a wide range of multimodal instructional materials, associated with digital communication environments, which are required for meaningful participation in a changing society (Mills, 2006). Teachers need to use innovative digital technologies and new literacy pedagogies to improve reading ability of second language learners. The findings also indicated that multimodal learning is more effective than traditional unimodal learning due to the fact that adding visuals to verbal learning can result in significant gains in higher-order learning. Multimodal instructional materials facilitate reading comprehension process through the interaction between texts and images. Multimodal texts, especially non-printed texts improve learners' pronunciation due to providing language learners with the opportunity to listen to the texts. Multimodal texts also increase language learners' motivation to process reading comprehension texts. Second language learners, who use multimodal texts, are more motivated to deeply process reading texts than those who use linear texts.

\section{References}

Block, C., \& Pressley, M. (2002). Comprehension instruction: research-based best practices. New York: Guilford Press.

Bobis, J., Sweller, J. \& Cooper, J. (1993). Cognitive load effects in primary-school geometry task. Learning and Instruction, 3, 1-21. http://dx.doi.org/10.1016/S0959-4752(09)80002-9

Bowen, B., M. (1982). Look here! Visual aids in language teaching. London: Macmillan.

Chandler, P. \& Sweller, J. (1991). Cognitive load theory and the format of instruction. Cognition and Instruction, 8, 293-332. http://dx.doi.org/10.1207/s1532690xci0804_2

Chayaburakul, S. (2003). Teaching English methods. Offset creation, Bangkok, Thailand.

Day, R. R. \& Bamford, J. (1998). Extensive reading in the second language classroom. New York: Cambridge University Press. http://dx.doi.org/10.1177/003368829802900211

Gerrig, R., \& McKoon, G. (1998). The readiness is all: the functionality of memory-based text processing. Discourse Processes, 26, 67-86. http://dx.doi.org/10.1080/01638539809545039

Grabe, W. (2004).Research on teaching reading. Annual Review of Applied Linguistics, 24, 44-69. http://dx.doi.org/10.1017/S0267190504000030

Grabe, W. Stoller. \& F. L. (2002). Teaching and Researching Reading. London: Pearson Education. http://dx.doi.org/10.1017/S0267190504000030

Halliday, M. A. K. (1976). System and function in language. London: Oxford University Press.

Harp, S. \& Mayer, R. E. (1997). Role of interest in learning from scientific text and illustrations: On the distinction between emotional interest and cognitive interest. Journal of Educational Psychology, 89, 92-102. http://dx.doi.org/10.1037//0022-0663.89.1.92

Karimi, A. (1386). The most important results of the 2006 national and international PIRLS 2006 compared with 2001. Tehran: Institute of Education Press.

Kintsch, W. (1988). The use of knowledge in discourse processing: a construction-integration model. Psychological Review, 95, 163-182.

Koda, K. (2005). Insights into Second Language Reading. A Cross-Linguistics Approach. Cambridge: Cambridge University Press. http://dx.doi.org/10.1017/CBO9781139524841

Kuhn, M. R. \& Stahl, S. A. (2003). Fluency: A review of developmental and remedial practices. Journal of Educational Psychology, 95(1), 3-21. http://dx.doi.org/10.1037//0022-0663.95.1.3

Kress, G. \& van Leeuwen, T. (1996). Reading Images: The Grammar of Visual Design, London: Routledge.

Kress, G. \& van Leeuwen, T. (2001.) Multimodal Discourse, London: Arnold.

Kuo, Y. C., Yang, S.-W. \& Kuo, H.-H. (2010). Learning Bridge: A Reading Comprehension Platform with Rich Media. World Academy of Science, Engineering and Technology, 934-936.

Mayer, R. E. (1997). Multimedia learning: Are we asking the right questions. Educational Psychologist, 32, 1-19. http://dx.doi.org/10.1207/s15326985ep3201_1

Mayer, R. E. (1989). Systematic thinking fostered by illustrations in scientific text. Journal of Educational Psychology, 81, 240-246. http://dx.doi.org/10.1037//0022-0663.81.2.240

Mayer, R. (2001). Multi-Media Learning. Cambridge: Cambridge University Press.

Mayer, R. E. (2009). Advances in applying the science of learning and instruction to education. Psychological Science in the Public Interest, 9 (3), pp. i-ii. http://dx.doi.org/10.1111/j.1539-6053.2009.01037.x 
Mayer, R. E. \& Anderson, R. B. (1991). Animations need narrations: An experimental test of a dual-coding hypothesis. Journal of Educational Psychology, 83, 484-490. http://dx.doi.org/10.1037//0022-0663.83.4.484

Mayer, R. E. \& Anderson, R. B. (1992). The instructive animation: Helping students build connections between words and pictures in multimedia learning. Journal of Educational Psychology, 444-452. http://dx.doi.org/10.1037//00220663.84.4.444

Mayer, R. E., Bove, W., Bryman, A., Mars, R. \& Tapangco, L. (1996). When less is more: Meaningful learning from visual and verbal summaries of science textbook lessons. Journal of Educational Psychology, 88, 64-73. http://dx.doi.org/10.1037//0022-0663.88.1.64

Mayer, R. E. \& Gallini, J. K. (1990). When is an illustration worth ten thousand words? Journal of Educational Psychology, 82 (4), 715-726. http://dx.doi.org/10.1037//0022-0663.82.4.715

Mayer, R. \& Moreno, A. (1998). Split-attention effect in multimedia learning: evidence for dual processing systems in working memory. Journal of Educational Psychology, 312-320. http://dx.doi.org/10.1037//00220663.90.2.312

Mayer, R. E. \& Sims, V. K. (1994). For whom is a picture worth a thousand words? Extensions of a dual-coding theory of multimedia learning. Journal of Educational Psychology, 86, 389-401. http://dx.doi.org/10.1037//00220663.86.3.389

Mayer, R. E., Steinhoff, K., Bower, G. \& Mars, R. (1995). A generative theory of textbook design: Using annotated illustrations to foster meaningful learning of science text. Educational Technology Research and Development, 31-44. http://dx.doi.org/10.1037//0022-0663.86.3.389

Mills, K. A. (2006). Multiliteracies: A critical ethnography: Pedagogy, power, discourse and access to multiliteracies. Unpublished $\mathrm{PhD}$ thesis, Queensland University of Technology, Brisbane.

Mousavi, S. Y., Low, R. \& Sweller, J. (1995). Reducing cognitive load by mixing auditory and visual presentation modes. Journal of Educational Psychology, 87, 319-334. http://dx.doi.org/10.1037//0022-0663.87.2.319

Paas, F. G. W. \& Van Merrienboer, J. G. (1994). Instructional control of cognitive load in the training of complex cognitive tasks. Educational Psychology Review, 6, 351-372. http://dx.doi.org/10.1007/BF02213420

Perfetti, C. A. (1999). Comprehending written language: A blueprint of the reader. In C. M.Brown, \& P. Hagoort, The neurocognition of language processing (pp. $167-208$ ). London: Oxford University Press.

Roe, D. B. \& Ross P. E. (2006). Integrating Language Arts through Literature and Thematic Unit. Pearson

Segers, E. V. \& Hulstijn-Hendrikse, N. (2008). Cognitive processes in children's multimedia text learning. Applied Cognitive Psychology, 22, 375-387. http://dx.doi.org/10.1002/acp.1413

Son, J. (2003). A hypertext approach to foreign language reading: Student attitudes and perceptions.Australian Review of Applied Linguistics, 17, 91-110

Sweller, J. \& Chandler, P. (1994). Why some material is difficult to learn. Cognition and Instruction, 12, 185-233. http://dx.doi.org/10.1207/s1532690xci1203_1

Sweller, J., Chandler, P., Tierney, P. \& Cooper, M. (1990). Cognitive load as a factor in the structure of technical material. Journal of Experimental Psychology: General, 119, 176-192. http://dx.doi.org/10.1037//0096-3445.119.2.176

Taylor, B.M.,Graves, M.E. \& Broek, P.V.D (2000) (Eds.) Reading for meaning: Fostering comprehension in the middle grades, International Reading Association, Newark, 1-31

Van den Broak, P., Kremer, K. (2000). The mind in action: What it means to comprehend during reading .In B.M. Taylor, P.Van den Broek,\& M. Graves (Eds), Reading for meaning (pp. 1-31). New York: Teachers College Press.

Van den Broek, P., Risden, K., Fletcher, C. R., \& Thurlow, R. (1996). A "landscape" view of reading: Fluctuating patterns of activation and the construction of a stable memory representation. In: B. K.Britton \& A. C. Graesser (Eds.), Models of understanding text (pp. 165-187). Hillsdale, NJ:Lawrence Erlbaum.

Verhoeven, L. \& Perfetti, C. (2008). Introduction advances in text comprehension: model, process and development. Applied Cognitive Psychology, 22, 293 - 301.

Walsh, M. (2006). Reading visual and multimodal texts: how is 'reading' different? Australian Journal of Language and Literacy, 29, 24-37. 